\title{
The Roles of Spiritual Well-being and Tolerance of Uncertainty in Prediction of Happiness in Elderly
}

\author{
1 Eghlid Branch, Islamic Azad University (Iran). \\ 2 Lorestan University (Iran).
}

Siamak Khodarahimi ${ }^{1}$, Ezatolah Ghadampour ${ }^{2,}$, and Amir Karami ${ }^{2}$

\begin{abstract}
Título: Los roles del bienestar espiritual y la tolerancia a la incertidumbre en la predicción de la felicidad en los ancianos.

Resumen: Antecedentes: De acuerdo con las conceptualizaciones del bienestar espiritual, la intolerancia a la ambigüedad y la felicidad, este estudio tuvo como objetivo investigar las influencias del bienestar espiritual y la tolerancia a la incertidumbre sobre la felicidad con respecto a los roles moderadores del sexo en los ancianos. Método: Los participantes incluyeron a 120 an cianos de la ciudad de Shiraz, provincia de Fars, Irán. Para la recopilación de datos se utilizaron un cuestionario demográfico, el Inventario de Bienestar Espiritual (SWBI), la Escala II de Tolerancia a la Ambigüedad de Tipos de Estímulos Múltiples (MSTAT-II) y el Cuestionario de Felicidad de Oxford (OHI). Resultados: Los resultados mostraron que la espiritualidad, el bienestar y la intolerancia a la incertidumbre explican el 60\% de la variación de la felicidad en los ancianos. Pero los resultados rechazaron el papel de sexo en la predicción de la felicidad en el presente estudio. Conclusión: Este estudio demuestra los roles predictivos del bienestar espiritual y la tolerancia a la ambigüedad sobre la felicidad en el campo de la gerontología.

Palabras clave: Bienestar espiritual. Tolerancia a la incertidumbre. Felicidad. Sexo. Anciano.
\end{abstract}

\begin{abstract}
Background: According to spirituality well-being, ambiguity intolerance, and happiness conceptualizations, this study was purposed to investigate the influences of spiritual well-being and uncertainty tolerance on happiness with regards to the moderating roles of sex in the elderly. Method: Participants included 120 elders from Shiraz City, Fars province, Iran. A demographic questionnaire, the Spiritual Well-Being Inventory (SWBI), the Multiple Stimulus Types Ambiguity Tolerance Scale-II (MSTAT-II), and the Oxford Happiness Questionnaire $(\mathrm{OHI})$ were used for data collection. Results: Findings showed that spirituality well-being and uncertainty intolerance explain $60 \%$ of happiness variation in the elderly. But results rejected the role of sex on the prediction of happiness in the present study. Conclusion: This study demonstrates the predictive roles of spiritual wellbeing and ambiguity tolerance on happiness in the field of gerontology. Keywords: Spirituality well-being. Uncertainty tolerance. Happiness. Sex. Elderly.
\end{abstract}

\section{Introduction}

Initially, Brooke (1987) showed the importance of the spirituality construct as a way to search for meaning of age-related experiences which help elders cope efficiently with physical and mental problems. Lavretsky (2010) showed that health outcomes such as the issues of loss, physical illness, and mortality are associated with the size of mortality in the elderly. Jackson et al. (2016) showed the value and healing roles of nurses and other aged care staff in the promotion of spiritual care for the improvement of later healthy life in older people. Overall, the aging phenomenon will be linked with the growing prevalence of spiritual activity in the world. However, numerous studies in the field of spirituality among the elderly have done in the U.S. and Europe (Zimmer et al., 2016).

Jafari, Loghmani, and Puchalski (2014) showed that spirituality is a fundamental element of health care in Iran. Koenig, Zaben, and Khalifa (2012) showed there is a substantial overlap between Christian and Muslim spiritual and religious groups in their beliefs, practices of worship, moral beliefs and values, and the emphasis on family life. Because

* Correspondence address [Dirección para correspondencia]: Ezatolah Ghadampour:, PhD, Psychology Department, School of Literature and Humanities Sciences, Lorestan University, 5th Kilometer of horramabad-Boroujerd Highway, P. O. Box 465, Khorramabad 68151-44316, Lorestan (Iran). E-mail: ghadampour.e@lu.ac.ir

(Article received: 27-09-2020, revised: 09-12-2020, accepted: 21-12-2020) of the similarity in faith and practice among these religions, they showed that religious involvement in both religious traditions has tended to produce similar results on their mental health. Weathers (2018) stated that there are both differences and similarities between Middle Eastern and Western research on spirituality. Research indicated relationships among spirituality, mental health problems, and psychological well-being (PWB) in older people (Kirby et al., 2004; Perinotti-Molinatti, 2005; Piderman et al., 2011). Though age and gender were not significant predictors of spiritual wellbeing in the elderly (Griffin et al., 2007; Velasco-Gonzalez \& Rioux, 2014). Nevertheless, evidence in this area has as well shown that gender difference exists, with the most solid spirituality being held by women (King et al., 2001; Vosloo et al., 2009). Therefore, this study is intended to investigate the roles of spiritual well-being and tolerance of uncertainty in the prediction of happiness with regards to the moderating role of gender in the elderly.

Intolerance of uncertainty (IU) is a trans-diagnostic concept involved in anxiety and related disorders (Mosca et al., 2016). IU means the perception of uncertainty as threatening, regardless of the true probability of threat in the real world, and it is related to anxiety and depression symptoms (Tanovic et al., 2018). Thereby, elders with little knowledge about aging who have a high intolerance of uncertainty may experience an aggravation of pathological worry. Whilst elders with greater knowledge about aging may be less expected to entertain negative stereotypes, they are more tolerant of uncertainty related to aging, and thus less prone to se- 
vere worry (Dugas et al., 1997; Nuevo et al., 2009). Research showed that disruptions in several domains of responding to uncertainty, danger, and reward are linked with IU that may increase the risk for the development of psychopathology (Tanovic et al., 2018). Older and younger adults have differences in ambiguity resolution due to their age-related changes in decision making, processing of negative emotional information, and language symbols (Bucks et al., 2008; Dagerman et al., 2006; Kachmaryk et al., 2014; Sproten et al., 2010). Altogether, studies showed that IU has a significant role in affective disorders and affect states of individuals (Anderson et al., 2019; Mosca et al., 2016). Particularly, studies indicated that older adults report less intolerance of uncertainty and less belief in the functional value of worrying compared to younger adults (Basevitz et al., 2008). Furthermore, the attainment of good knowledge and instructional programs of the aging process could help to reduce aversive uncertainty and the level of worry among older adults (Nuevo et al., 2009). Research indicated that gender is not influential in tolerating uncertainty in the elderly (Nuevo et al., 2009). A new trend of investigations emerged about the relationship of spirituality with intolerance of ambiguity and happiness in the elderly (Boonroungrut \& Worakul, 2009; de Guzman et al., 2015).

Similarly, investigations showed that psychological factors and age may influence happiness in older adults who are living in the community (Luchesi et al., 2018). Scortegagna, Pichler, and Fáccio (2018) indicated that Spirituality can increase happiness among institutionalized elderly individuals. Adib-Hajbaghery and Faraji (2015) showed that most of the elders who living in the community and in sanitariums have significantly lower happiness. Also, studies found that formal education, geographical areas, and gender can influence happiness among the elderly (Hori, \& Kamo, 2018; Sumngern et al., 2010).

Finally, Gomez and Fisher (2003) showed that the total spiritual well-being, and personal, communal, and environmental components of spiritual well-being have significantly positive correlations with happiness. Argyle and Hills (2000) reported that happiness is related to a spiritual factor ("Immanent") which reflects Fisher's personal and transcendental well-being components.

\section{Theoretical frameworks}

Spirituality is considered as a set of beliefs, a search for meaningful and purposeful life, a sense of relationship with others, and a transcendence of self, that results in a perception of inner harmony (Delgado, 2005). In the field of spirituality well-being, there is a broad range of perspectives such as socioemotional selectivity, maturational process, disengagement, transcendence of personal self, religious wellbeing, general quality of life, and successful aging which try to explain spirituality in the later of life (Laubmeier et al., 2004; Lavretsky, 2010; O'Connell \& Skevington, 2010). Likewise, Fisher (1998) proposed a spiritual well-being mod- el with four personal, communal, environmental, and transcendental components, and a single global spiritual wellbeing integral. The personal component shows how individual interrelationships with oneself, with respect to meaning, purpose and principles in life. The communal component indicates in the quality and depth of interpersonal relations, between self and others, and this includes love, fairness, hope, and trust in humanity. The environmental component contains with care and encourage for the physical biosphere, including a sense of surprise, marvel and harmony with the environment. The transcendental component consists of the connection of self with somewhat or somebody outside the human level, such as a galactic power, supreme certainty, or God, and it covers faith towards, praise and worship of, the cause of clandestine of the world. Fisher (2000) also suggested that these four spiritual well-being domains cohere to determine a person's overall or global spiritual well-being.

Fisher (2000) proposed that the spiritual well-being is a holistic phenomenon. Thereby, an individual's spirituality seems to be specified by the combination of spiritual wellbeing in each of the domains embraced by the individuals (Fisher, Francis, \& Johnson, 2000). Although there is a lack of evidence that how the spiritual well-being is likely to be related to happiness in elderly. According to the spiritual well-being model (Fisher, 2000,1998); this study suggests that spirituality well-being can influence the experience of happiness in elderly individuals by guiding of their coping skills, lifestyles and behaviors.

In the field of ambiguity, IU has been defined as " a dispositional characteristic that results from a set of negative beliefs about uncertainty and its implications and involves the tendency to react negatively on an emotional, cognitive, and behavioral level to uncertain situations and events" (Buhr \& Dugas, 2009; p. 216). de Guzman, Lacao and Larracas (2015) identified four factor dimensions of uncertainty in elderly: perfection-driven uncertainty, apprehension-driven uncertainty, avoidance-driven uncertainty, and negativism-driven uncertainty. Intolerance of uncertainty may play a moderating influence between knowledge about aging and severity of worry (Buhr \& Dugas, 2009). According to an integrative and multidimensional conceptual model; uncertainty tolerance as the set of negative and positive psychological responses aggravated by the conscious awareness of innocence about the particular features of the world (Hillen et al., 2017). Rosmarin et al. (2011) proposed a cognitive model of worry, in which positive/negative attitudes about the Divine influence symptoms through the mechanism of intolerance of uncertainty. They conceptualised that low uncertainty tolerance may increase worry, and high tolerance of uncertainty increases happiness in general. Finally, Anderson and colleagues (2019) speculated that uncertainty and affect are central and interconnected features of the human nature. They argued that uncertainty is regularly linked with negative affect, but in some situations, it is related to positive affect. The present study suggests a bilateral relationship between uncertainty and happiness in the human condition. Thereby, high levels of uncertainty intolerance and experience of the 
recurrent uncertainty in the social world with increase of negative affect can reduce positive emotions such as happiness. Alternatively, high capability for uncertainty tolerance among people can help them to attain more happiness as a positive affect.

In the field of happiness, Veenhoven (2012) defined the overall happiness as the extent to which an individual judge the general quality of his/her own life in a full favorably outlook. Argyle (1987) suggests that happiness includes two components: life satisfaction with one's life in general and with different life's domains, and the rate of positive emotions such as elation or joy. Veenhoven (2009) identified two distinct sources of information when individuals evaluating the positivity of life: affects and thoughts. Finally, Veenhoven (2012) conceptualized the happiness as 'life satisfaction' and 'subjective well-being" in general. Diener (2006) defined happiness as a synonym of subjective well-being (SWB) as a global term for diverse types of evaluations, both positive and negative, that individuals formulate about their lives such as appraisals of life fulfillment, engagement, and affect. Diener (1984) differentiated between top-down and bottomup influential factors on SWB. Diener et al. (1999) described bottom-up factors as peripheral or external events, situations, and demographics. Top-down factors show personal factors (i.e. values and goals) that activate external events that influence well-being (Diener et al. 1999).

\section{The present study}

Altogether, the current literature in the field of spirituality well-being is considered the possible role of this construct in progress of psychological well-being such as happiness in elderly (Kirby et al., 2004; Perinotti-Molinatti, 2005; Piderman et al., 2011; Vosloo et al., 2009). In addition, a few studies found significant associations between spirituality wellbeing, ambiguity intolerance, and happiness in elderly (Argyle \& Hills, 2000; Boonroungrut \& Worakul, 2009; de Guzman, Lacao \& Larracas, 2015; Gomez \& Fisher, 2003). According to aforesaid theories in spirituality well-being (Fisher, 2000, 1998; Fisher et al., 2000; Laubmeier et al., 2004), uncertainty intolerance (Anderson et al., 2019; Buhr \& Dugas, 2009; de Guzman et al., 2015; Nuevo et al., 2009) and happiness (Veenhoven, 2012, Diener, 2006; Diener et al. 1999); this study suggests that spirituality well-being and uncertainty tolerance can help individuals to experience more happiness in elderly. This study is essential because there is a discontinuity in the literature regarding the concurrent potential roles of spirituality well-being and uncertainty tolerance with the moderating influence of gender in prediction of happiness, particularly in elderly. However, as noted already happiness in adulthood may be influenced by demographics such as gender. Thereby, it would expect gender to play a moderating role in the relationships between spirituality well-being, uncertainty tolerance and happiness in elderly. Specifically, it would expect that spirituality well-being and tolerance of uncertainty to be differently associated with happiness in men and women, and these constructs would have more contribution in happiness among women in elderly. The first hypothesis of this study is that spirituality well-being and ambiguity tolerance would have significant influences in prediction of happiness in elderly. The second hypothesis of this study is that gender would have a significant role in happiness styles.

\section{Method}

\section{Participants}

The participants included 120 elders (64-93 years old) which were recruited from Shiraz, Fars province, Iran. The sample included 60 males and 60 females. The mean age and standard deviation for males and females were 78.98 (SD = $8.32)$ and $79.51(S D=6.85)$ respectively. Of the total sample, 60 were resident in gerontology centers and 60 lived in their homes. Of 120 participants, 40 individuals were married, and 80 persons were single. The number of years of education in participants was eleven $(n=50)$, twelve $(n=60)$, and thirteen $(n=10)$ in the total sample. All participants were Fars ethnic and Muslims.

Sample size is determined with regards the research design and the vigorous statistic for multiple regression and hierarchical regression analysis (Rosenthal et al., 2000; Wilson et al., 2007). After informed consent, which was obtained, participants completed a demographic questionnaire with three inventories.

\section{Instruments}

A demographic questionnaire, the Spiritual Well-Being Inventory (SWBI), the Multiple Stimulus Types Ambiguity Tolerance Scale-II (MSTAT-II) and the Oxford Happiness Questionnaire $(\mathrm{OHI})$ were used for data gathering in this study. The demographic questionnaire involved participants' age and gender questions.

Spiritual Well-Being Inventory (SWBI; Dehshiri et al., 2013). The SWBI is a 40 -items self-rating measure that invented to evaluate personal spiritual well-being based on an inter-religion approach regarding the personal relationships with the divine, self, others, and nature (e.g., I feel satisfaction in my life). Items are structured on a five-point Likert type responses that ranging from 1 (never) to 5 (always). Dehshiri et al. (2013) reported an internal consistency reliability of .94 and test-retest reliability.86 for the SWBI. The SWBI showed an internal Cronbach's consistency reliability of .92 in the present study.

The Multiple Stimulus Types Ambiguity Tolerance Scale-II (MSTAT-II; Mclain, 2009): The MSTAT-II is a 13items measure that developed to assess an individual's cognitive tolerance range from aversion to attraction for situations that are unfamiliar, insoluble, or complex. The MSTAT-II measures the individual's level of ambiguity tolerance based on five stimulus types (e.g., I am tolerant of ambiguous situa- 
tions): 1) ambiguous stimuli in general, 2) complex stimuli, 3) uncertain stimuli, 4) new/unfamiliar/novel stimuli, and 5) insoluble/illogical/internally inconsistent stimuli. Items are structured as five-point Likert -type responses ranging from 1 (strongly disagree) to 5 (strongly agree). The individuals' low scores represent their aversion to ambiguity, while their high scores show their interest in ambiguity. McLain (2009) reported an internal consistency reliability of .83 for MSTAT-II. Also, the MSTAT-II psychometric properties are established in Iranian studies (Zhaleh, Ghonsooly, \& Pishghadam, 2018). The MSTAT-II showed an internal Cronbach's consistency reliability of .90 in the present study.

Oxford Happiness Questionnaire (OHI; Argyle et al. 1989). The OHI was a broadly used measurement device, and a measure of overall happiness. The OHI is a 29-item measure that assesses satisfaction, positive mood, health, efficacy and self-esteem dimensions (e.g., I am very happy). All items were rated on a 7-point Likert scale from 1 (Strongly disagree) to 7 (Strongly agree), with the higher scores equivalent to higher levels of happiness. OHI's alpha was .90 and a test retest reliability of .78 over 7 weeks and .67 over 5 months (Argyle et al. 1989). The psychometric properties of OHI are confirmed in Iranian studies (Khodarahimi, 2011, 2014; Khodarahimi \& Ogletree, 2011). The OHI showed an internal Cronbach's consistency reliability of .91 in the present study.

\section{Statistical analysis}

The SPSS 19 software was used for data analysis in the present investigation (Bryman \& Duncan, 2011). To assess the main hypotheses in this research analysis of multiple regression using enter procedure by spiritual well-being and tolerance of ambiguity as predictive variables and happiness as dependent variable were computed in this sample. Also, a hierarchical multiple regression analysis using sex as a "dummy" variable (with 0 and 1 values): first block, and sex plus spiritual well-being and tolerance of ambiguity, the second block, was computed in this study. The significance level of hypothesis testing was $\alpha=05$.

\section{Results}

To investigate the first hypothesis in this study, a multiple regression analysis with enter procedure was performed to evaluate the role of spirituality well-being and ambiguity tolerance on the prediction of happiness across the entire sample. Table 1 shows descriptive statistics and correlations among variables in this sample. First, Stem-and-Leaf Plot and normal q-q plot of spiritual well-being, ambiguity tolerance and happiness showed the linear relationships between independents and outcome variables without outliers or influential cases in each variable. In addition, there was no multicollinearity between spirituality well-being and ambiguity tolerance as independent variables (Table 1). All basic assumptions were satisfactory for running of multiple regression about this hypothesis (Durbin-Watson $=1.45$, Mahal. Distance $=1.98$, Tolerance $=.74$, Cook's Distance $=.008$, $\mathrm{VIF}=1.33$ ). Results showed that spiritual well-being and ambiguity tolerance predicted the happiness's variability in this sample, $R^{2}=.60, F(2,119)=153.52, p<.0001$ (Table 2).

Table 1

Ambiguity Tolerance in Elders. Mean, Standard Deviation and Correlations of Happiness, Spiritual Well-Being and.

\begin{tabular}{lcccc}
\hline Variables & $M$ & $S D$ & 1 & 2 \\
\hline Happiness & 123.09 & 27.53 & $.747^{* *}$ & $.564^{* *}$ \\
Independents: & & & & \\
1. Spirituality well-being & 40.77 & 8.41 & - & $.501^{* *}$ \\
2. Ambiguity tolerance & 48.02 & 6.47 & & - \\
\hline
\end{tabular}

Note: ${ }^{*} p<.05 .{ }^{* *} p<.01, n=120$.

Table 2

Summary of Multiple Regressions for Predictive V ariables of Happiness in the Total Sample.

\begin{tabular}{|c|c|c|c|c|c|c|c|}
\hline Model & $\mathrm{R}$ & $\mathrm{R}^{2}$ & $F$ & $B$ & SE B & $\beta$ & $t$ \\
\hline Spiritual well-being & .74 & .55 & $148.85^{* * *}$ & .447 & .03 & .747 & $12.201 * * *$ \\
\hline \multirow{2}{*}{$\begin{array}{l}\text { Spiritual well-being } \\
\text { Ambiguity tolerance }\end{array}$} & \multirow{2}{*}{.77} & \multirow{2}{*}{.60} & \multirow{2}{*}{$153.52 * *$} & .143 & .04 & .238 & $3.069 *$ \\
\hline & & & & 11.666 & 1.38 & .652 & $8.397 * *$ \\
\hline
\end{tabular}

Note: ${ }^{*} p<.05,{ }^{* *} p<.01,{ }^{* * *} p<.001$

To examine the second hypothesis for examination of the role of gender, spiritual well-being and ambiguity tolerance on happiness among elderly, a hierarchal multiple regression was used. All basic assumptions were satisfactory for running of multiple regression about this hypothesis (Durbin-Watson $=1.47$, Mahal. Distance $=2.97$, Tolerance $=.98$, Cook's Distance $=.008, \mathrm{VIF}=1.33)$. This analysis included sex as a "dummy" variable (with 0 for males and 1 value for females): first block, the spiritual well-being and ambiguity tolerance second block, and the third step: interaction spiritual well-being and ambiguity tolerance *sex. Again, this analysis only showed a significant difference for spiritual well-being and ambiguity tolerance; $R^{2}=.607, F(3,119)=$ $59.79, p<.0001$. This analysis rejected the role of sex and the interaction of sex with spiritual well-being and ambiguity tolerance on prediction of happiness in elderly (Table 3 ). 
Table 3

Summary of Hierarchical Regression Analysis for Variables Predicting Happiness in the Total Sample.

\begin{tabular}{|c|c|c|c|c|c|c|c|c|}
\hline \multirow[b]{2}{*}{ Variable } & \multicolumn{4}{|c|}{ Model 1 (Gender) } & \multicolumn{4}{|c|}{ Model 2 (Gender + Spirituality well-being + Ambiguity tolerance ) } \\
\hline & $B$ & SE B & $\beta$ & $t$ & $B$ & SE B & $\beta$ & $t$ \\
\hline Gender & .021 & 3.03 & .001 & .007 & 1.35 & 1.93 & .041 & .701 \\
\hline Spirituality well-being & & & & & .369 & .040 & .617 & $9.15^{* * *}$ \\
\hline Ambiguity tolerance & & & & & .509 & .133 & .260 & $3.82 * *$ \\
\hline$R^{2}$ & .0001 & & & & .607 & & & \\
\hline$F$ for change in $R^{2}$ & .0001 & & & & $59.79 * *$ & & & \\
\hline
\end{tabular}

Note: ${ }^{*} p<.05,{ }^{* * *} p<.0001, n=120$

\section{Discussion}

The results for the first hypothesis showed that spiritual well-being and ambiguity tolerance altogether predicted $60 \%$ of the happiness variability in elderly. These findings are congruent with the predictions of spirituality well-being (Fisher, 2000; Fisher et al., 2000; Laubmeier et al., 2004) and uncertainty intolerance (Buhr \& Dugas, 2009; de Guzman et al., 2015; Nuevo et al., 2009) theories of development of happiness (Veenhoven, 2012, Diener, 2006; Diener et al. 1999) in elderly. In line with previous studies (Fisher, 2000, 1998; Fisher et al., 2000; Laubmeier et al., 2004), it seems that spiritual well-being as an interpersonal perception toward the whole meaning of the life may direct and guide the path of mental health during elderly. Alternatively, in agreement with predictions of uncertainty intolerance theories, particularly an integrative and multidimensional conceptual model of uncertainty (Buhr \& Dugas, 2009; de Guzman et al., 2015; Hillen et al., 2017; Nuevo et al., 2009), this study suggests that spirituality help elders to more tolerate the high levels worry which is resulting from of different sources of uncertainty in their lives. However, it seems that faith and positive beliefs about the Divine is probably independent of traditional religions the culture of elders. Perhaps such beliefs only produce hope for redemption in the general sense, and thereby it influences the occurrence of personal satisfaction and happiness in elders. This explanation for the possible roles of spiritual well-being and ambiguity tolerance on prediction of happiness among elders is often congruent with inherent life-satisfaction and subjective well-being components in happiness theories (Diener, 2006; Veenhoven, 2012). Moreover, the present results are consistent with the literature which supported the role of spirituality and uncertainty tolerance in progress of psychological well-being status, such as happiness in elderly (Boonroungrut \& Worakul, 2009; de Guzman et al., 2015; Kirby et al., 2004).

Altogether, this study speculates that high spirituality well-being and ambiguity tolerance are positively related to the highest levels of happiness in elders. This study suggests that spirituality well-being and ambiguity tolerance constructs and be considered as two top-down interpersonal resources which help individuals to attain the greatest happiness in elderly. Because life satisfaction and subjective or phenomenological well-being are shared between spiritual well-being, ambiguity tolerance and happiness and all three constructs originally related to the personal best interpretation of self, the world and interconnections between self and world and their relations with the Divine. This explanation seems more logical when is considered in the light of results for the second hypothesis. Again, results from the second hypothesis rejected the role of gender on prediction of happiness, but showed that spiritual well-being and ambiguity tolerance altogether predicted $60 \%$ of the happiness variability within a hierarchical regression model in elderly. As noted already, these positive effects of spiritual well-being and ambiguity tolerance constructs on happiness beyond the gender can be explained in the light of life phenomenological perception of life satisfaction and subjective well-being in elders which they put on both negative and positive facts of their lives from a holistic perspective.

This study adds to the present literature with regards to the influences of spiritual well-being and ambiguity tolerance on prediction of happiness in elderly. In an evidence-based conceptualization and practice, these findings have implications in the field of gerontology for enhancement of happiness and its correlated constructs. Mental health and gerontology professionals and community well-being policy makers may use these findings for measurement, prevention and empowerment goals in elders. Furthermore, results from the present study can be applied for educational and teaching purposes in both clinical and academic fields. However, the present study has limitations because it has only used three self-rated measures only in elderly males and females. Next studies are crucial to explore the role of spiritual well-being and ambiguity tolerance of happiness among clinical and non-clinical samples of elders by using of longitudinal/cohorts or experimental designs and both quantitative and qualitative measures. Upcoming inquiries should be investigating how spiritual well-being and ambiguity tolerance may influence the happiness of believers to other religions and non-religious individuals in elderly. Ultimately, spiritual well-being and religiosity are two discriminated constructs, and further investigations essential to explore how religiosity and ambiguity tolerance can predict happiness in elderly with regards to the moderating role gender.

Acknowledgement.- Authors are grateful to Mercedes Ovejero Bruna, Complutence University, Madrid, Spain; for her copy editions in this article. 


\section{References}

Adib-Hajbaghery, M., \& Faraji, M. (2015). Comparison of happiness and spiritual well-being among the community dwelling elderly and those who lived in sanitariums. International journal of community-based nursing and midwifery, 3(3), 216-26.

Anderson, E.C., Carleton, R. N., Diefenbach, M., \& Han, P. K. J. (2019). The relationship between uncertainty and affect. Frontiers in Psychology, 10 (2504), 1-17. https://doi.org/10.3389/ fpsyg.2019.02504

Argyle, M. (1987). The psychology of happiness. New York, NY, US: Methuen.

Argyle, M., \& Hills, P. (2000). Religious experiences and their relations with happiness and personality. The International Journal for the Psychology of Religion, 10(3), 157-172.

Basevitz, P., Pushkar, D., Chaikelson, J., Conway, M., \& Dalton, C. (2008). Age-related differences in worry and related processes. International journal of aging \& buman development, 66, 283-305. https://doi.org/10.2190/AG.66.4.b

Boonroungrut, C., \& Worakul, P. (2009). Spiritual well-being and happiness in the elderly at Ban Bang Khae Social Welfare Development Center., Thailand. Journal of Religious and Culture, 2, 153-166.

Brooke, V. (1987). The spiritual well-being of the elderly. Geriatric Nursing, 8(4), 194-195. http://doi.org/10.1016/S0197-4572(87)80222-7

Bryman, A., \& Duncan, C. (2011). Quantitative data analysis with IBM SPSS 17, 18 and 19: A guide for social scientists. New York: Routledge.

Bucks, R. S., Garner, M., Tarrant, L., Bradley, B. P., \& Mogg, K. (2008). Interpretation of emotionally ambiguous faces in older adults. Journal of Gerontology: Psychological Sciences, 63(6), P337-343.

Buhr, K., \& Dugas, M.J. (2009). The role of fear of anxiety and intolerance of uncertainty in worry: An experimental manipulation. Behaviour Research and Therapy, 47, 215-223.

Dagerman, K. S., Macdonald, M. C., \& Harm, M. W. (2006). Aging and the use of context in ambiguity resolution: complex changes from simple slowing. Cognitive Science, 30(2), 311-345. https://doi.org/10.1207/s15516709 $\operatorname{cog} 000046$

Dehshiri, G., Najafi, M., Sohrabi, F., \& Traghikhah, S. (2012). Development and validation of spiritual wee-being inventory in students. Psychological Studies (Motaleat-e-Ravanshenakbti), 4(9), 73-98. http://psychstudies.alzahra.ac.ir/article 1759 b1b06a85df7a882ad9b4 26aef071de21.pdf

de Guzman, A. B., Lacao, R. A., \& Larracas, C. (2015). A Structural Equation Modelling on the Factors Affecting Intolerance of Uncertainty and Worry Among a Select Group of Filipino Elderly. Educational Gerontology, 41(2), 106-119. https://doi.org/10.1080/03601277.2014.918837

Diener, E. (2006). Guidelines for national indicators of subjective well-being and ill-being. Journal of Happiness Studies, 7, 397-404.

Diener, E. (1984). Subjective well-being. Psychological Bulletin, 95, 542-575.

Diener, E., Suh, E. M., Lucas, R. E., \& Smith, H. L. (1999). Subjective wellbeing: Three decades of progress. Psychological Bulletin, 125, 276-302.

Delgado, C. (2005). A Discussion of the Concept of Spirituality. Nursing Science Quarterly, 18(2), 157-162. https://doi.org/10.1177/0894318405274828

Dugas, M.J., Freeston, M.H., \& Ladouceur, R. (1997). The intolerance of uncertainty scale: Psychometric properties of the English version. Cognitive Therapy and Research, 21, 593-606.

Fisher, J. W. (2000). Being human and becoming whole: Understanding spiritual health and well-being. Journal of Christian Education, 43(3), 37-52.

Fisher, J.W. (1998). Spiritual health: Its nature, and place in the school curriculum. Unpublished doctoral dissertation, The University of Melbourne, Melbourne, Victoria, Australia.

Fisher, J.W., Francis, L.J., \& Johnson, P. (2000). Assessing spiritual health via four domains of spiritual well-being: The SH4DI. Pastoral Psychology, 49(2), 133-145.

Hillen, M. A., Gutheil, C. M., Strout, T. D., Smets, E. M. A., \& Han, P. K. J. (2017). Tolerance of uncertainty: Conceptual analysis, integrative mod$\mathrm{el}$, and implications for healthcare. Social Science \& Medicine, 180, 62-75. https://doi.org/10.1016/i.socscimed.2017.03.024

Jackson,D., Doyle,C., Capon, H., \& Pringle, E. (2016). Spirituality, spiritual need, and spiritual care in aged care: What the literature says. Journal of
Religion, Spirituality \& Aging, 28(4), 281-295. https://doi.org/10.1080/15528030.2016.1193097

Gomez, R. \& Fisher, J.W. (2003). Domains of spiritual well-being and development and validation of the Spiritual Well-Being Questionnaire. Personality and Individual Differences, 35(8),1975-1991. https://doi.org/10.1016/S0191-8869(03)00045-X

Griffin, M. T., Lee, Y. H., Salman, A., Seo, Y., Marin, P. A., Starling, R. C., \& Fitzpatrick, J. J. (2007). Spirituality and well-being among elders: differences between elders with heart failure and those without heart failure. Clinical interventions in aging, 2(4), 669-675. https://doi.org/10.2147/cia.s874

Jafari, N., \& Loghmani, A., \& Puchalski, C.M. (2014). Spirituality and health care in Iran: Time to Reconsider. Journal of Religion and Health, 53(6), 918-922. https://doi.org/10.1007/s10943-014-9887-2

Hori, M., \& Kamo, Y. (2018). Gender differences in happiness: The effects of marriage, social roles, and social support in East Asia. Applied Research in Quality of Life, 13(4), 839-857. https://doi.org/10.1007/s11482-017-9559-y

Kachmaryk, K., Grabovska, S., Ostrovska, K., \& Syniev, V. (2014). Tolerance for uncertainty in elderly people. Journal of Education Culture and Society, 1, 20-27. https://doi.org/10.15503/jecs20141-20-27

Khodarahimi, S. (2011). Happiness and worry in an Iranian adolescent and young adults sample. International Journal of Psychology and Counselling, 3(4),71-78.

Khodarahimi, S. (2014). The role of gender on positive psychology constructs in a sample of Iranian adolescents and young adults. Applied Research in Quality Life, 9(1), 45-61. https://doi.org/10.1007/s11482-013$\underline{9212-3}$

Khodarahimi, S. , \& Ogletree, S.L. (2011). Birth order, family size, and positive psychological constructs: What role do they play for Iranian adolescents and young adults? The Journal of Individual Psychology, 67(1), 4156.

King, M., Speck, P., \& Thomas, A. (2001). The royal free interview for spiritual and religious beliefs: Development and validation of a self-report version. Psychological Medicine, 31, 1015-1023.

Kirby, SE., Coleman, P.G., \& Daley, D. (2004). Spirituality and Well-Being in Frail and Nonfrail Older Adults, The Journals of Gerontology: Series B, Volume 59, Issue 3, 1, 123-129, https://doi.org/10.1093/geronb/59.3.P123

Koenig, H., Zaben, F., \& Khalifa, D. (2012). Religion, spirituality and mental health in the West and the Middle East. Asian journal of psychiatry, 5, 180-2. https://doi.org/10.1016/i.ajp.2012.04.004

Kumar, A., \& Dixit, V. (2017). Altruism, happiness and health among elderly people. Indian Journal of Gerontology, 31(4),480-496.

Laubmeier, K.K., Zakowski, S.G., \& Bair, J.P. (2004).The role of spirituality in the psychological adjustment to cancer: a test of the transactional model of stress and coping. International Journal of Behavioral Medicoine, 11(1), 48-55.

Lavretsky, H. (2010). Spirituality and aging. Aging Health, 6, 749-769. https://doi.org/10.2217/ahe.10.70

Luchesi, B. M., de Oliveira, N. A., de Morais, D., de Paula Pessoa, R. M. Pavarini, S. C. I., \& Chagas, M. H. N. (2018). Factors associated with happiness in the elderly persons living in the community. Archives of Gerontology and Geriatrics, 74, 83-87. doi: https://doi.org/10.1016/j.archger.2017.10.006

Mclain, David. (2009). Evidence of the properties of an ambiguity tolerance measure: The Multiple Stimulus Types Ambiguity Tolerance Scale-II $\begin{array}{lllll}\text { (MSTAT-II) } & \text { 1. Psychological reports, 105, 975-88. }\end{array}$ https://doi.org/10.2466/PR0.105.3.975-988

Mosca, O., Lauriola, M., \& Carleton, R. N. (2016). Intolerance of Uncertainty: A Temporary Experimental Induction Procedure. PloS one, 11(6), e0155130. https://doi.org/10.1371/journal.pone.0155130

Nuevo, R., Wetherell, J. L., Montorio, I., Ruiz, M. A., \& Cabrera, I. (2009). Knowledge about aging and worry in older adults: testing the mediating role of intolerance of uncertainty. Aging \& mental health, 13(1), 135-41. https://doi.org/10.1080/13607860802591088 
O'Connell, K. A., \& Skevington, S. M. (2010). Spiritual, religious, and personal beliefs are important and distinctive to assessing quality of life in health: A comparison of theoretical models. British Journal of Health Psy$\begin{array}{llll}\text { chology, } & 15(4), & 729 & -748 .\end{array}$ https://doi.org/10.1348/135910709X479799

Perinotti-Molinatti, J. (2005). The significance of sirituality in the elderly. A Dissertation Presented to the Faculty of Argosy University/Sarasota, Boca Raton, Florida.

Piderman, K. M., Lapid, M. I., Stevens, S. R., Ryan, S. M., Somers, K. J., Kronberg, M. T., Clark, M.M., \& Rummans, T. A. (2011). Spiritual well-being and spiritual practices in elderly depressed psychiatric inpatients. Journal of Pastoral Care \& Counseling, 65(1), 1-11. https://doi.org/10.1177/154230501106500103

Rosenthal, R., Roow, R.L., Rubin, D.B. (2000). Contrasts and effect sizes in behavioral research: A correlational approach. New York: Cambridge University.

Rosmarin, D. H., Pirutinsky, S., Auerbach, R. P., Bjorgvinsson, T., BigdaPeyton, J., Andersson, G., . . Krumrei, E. J. (2011). Incorporating spiritual beliefs into a cognitive model of worry. Journal of Clinical Psychology, 67(7), 691-700. https://doi.org/10.1002/jclp.20798

Scortegagna, H. d. M., Pichler, N. A., \& Fáccio, L. F. (2018). The experience of spirituality among institutionalized elderly people. Revista Brasileira de Geriatria e Gerontologia, 21, 293-300.

Sproten, A., Diener, C., Fiebach, C., Schwieren, C. (2010). Aging and decision making: How aging affects decisions under uncertainty. Discussion Paper Series, 508, 1-22.

Sumngern, C., Azeredo, Z., Subgranon, R., Sungvorawongphana, N., \& Matos, E. (2010). Happiness among the elderly in communities: A study in senior clubs of Chonburi Province, Thailand. Japanese Journal of Nursing Sciences, 7(1), 47-54. https://doi.org/10.1111/j.1742-7924.2010.00139.x

Tanovic, E., Gee, D., \& Joormann, J. (2018). Intolerance of uncertainty: Neural and psychophysiological correlates of the perception of uncertainty as threatening. Clinical Psychology Review, 60, 87-99. https://doi.org/10.1016/j.cpr.2018.01.001
Tymula, F., Belmaker, L. A. R., Ruderman, L., Glimcher, P. W., and Levy, I. (2014). Like cognitive function, decision making across the life span shows profound age-related changes. PNAS, 110 (42), 17143-17148, https://doi.org/10.1073/pnas.1309909110

Veenhoven, Ruut. (2009). 3. How do we assess how happy we are? Tenets, implications and tenability of three theories. Happiness, economics and politics: towards a multi-disciplinary approach. In A.K. Dutt and B. Radcliff, B. (eds.) 'Happiness, Economics and Politics: Towards a multidisciplinary approach', pp45-69; Edward Elger Publishers: Cheltenham UK

Veenhoven, R. (2012). Happiness: Also Known as "Life Satisfaction" and "Subjective Well-Being". In K. C. Land, A. C. Michalos \& M. J. Sirgy (Eds.), Handbook of Social Indicators and Quality of Life Research (pp. 63-77). Dordrecht: Springer Netherlands.

Velasco-Gonzalez, L., \& Rioux, L. (2014). The spiritual well-being of elderly people: a study of a French sample. Journal of Religion \& Health, 53(4), 1123-1137. https://doi.org/10.1007/s10943-013-9710-5

Vosloo, C., Wissing, M.P., \& Temane, Q.M. (2009). Gender, spirituality and psychological well-being. Journal of Psychology in Africa, 19(2), 153-159. https://doi.org/10.1080/14330237.2009.10820274

Weathers, E. (2018). Spirituality and Health: A Middle Eastern Perspective. Religions, 9(2), 33. https://doi.org/10.3390/rel9020033

Wilson VanVoorhis, C. R., \& Morgan, B.L. (2007).Understanding power and rules of thumb for determining sample sizes. Tutorials in Quantitative Methods for Psychology, $3(2), \quad$ 43-50. https://doi.org/10.20982/tqmp.03.2.p043

Zhaleh, K., Ghonsooly, B., \& Pishghadam, R. (2018). Effects of conceptions of intelligence and ambiguity tolerance on teacher burnout: A case of Iranian EFL teachers. Journal of Research in Applied Linguistics, 9(2), $118-140$

Zimmer, Z., Jagger, C., Chiu, C. T., Ofstedal, M. B., Rojo, F., \& Saito, Y. (2016). Spirituality, religiosity, aging and health in global perspective: A review. SSM Population Health, 2, 373-381. https://doi.org/10.1016/j.ssmph.2016.04.009 